\title{
TIPO DA LEI MORAL NA CRÍTICA DA RAZÃO PRÁTICA
}

\section{ARTIGO ORIGINAL}

NETO, Silvio Couto ${ }^{1}$

CANDIOTTO, Cesar ${ }^{2}$

NETO, Silvio Couto. CANDIOTTO, Cesar. Tipo da lei moral na crítica da razão prática. Revista Científica Multidisciplinar Núcleo do Conhecimento. Ano 05, Ed. 12, Vol. 01, pp. 87-97. Dezembro de 2020. ISSN: 2448-0959, Link de acesso:https://www.nucleodoconhecimento.com.br/sem-categoria/razao-pratica

\section{RESUMO}

No presente trabalho pretende-se fazer uma abordagem sobre a questão do tipo da lei moral como tratado por Immanuel Kant em sua obra Crítica da Razão Prática, buscando-se um enfoque explicativo sobe tal ponto e, naquilo que se mostrar possível, uma comparação ao tipo penal, utilizado na teoria do direito penal; isso porque o tipo da lei moral tem propósito semelhante ao tipo da lei moral, qual seja, possibilitar a compreensão da lei. A lei moral - que é totalmente isenta de influência de qualquer elemento natural, sensível, ditada unicamente pela razão livre e a priori, sem condicionantes externos - poderá ser compreendida, a partir do tipo através de modelos existentes no mundo natural, fenomênico, elementos, por isso mesmo, concretos e sensíveis.

${ }^{1}$ Doutorado em andamento pela Pontifícia Universidade Católica do Paraná - PUCPR, Escola de educação e Humanidades - Programa de Pós-Graduação em Filosofia; Mestre em Ciências Sociais Aplicadas pela Universidade Estadual de Ponta Grossa; Especialista em Direito Processual Penal Pela PUC-PR e graduado em Direito.

2 Orientador. Doutorado em Filosofia. Mestrado em Educação. Aperfeiçoamento em Pesquisa. Graduação em Teologia. Graduação em Teologia. 
Palavras-chave: razão prática, máxima, lei moral, tipo moral, Kant.

\section{INTRODUÇÃO}

Immanuel Kant, nascido na Prússia (atual Alemanha), em 22 de abril de 1724, é um dos mais conhecidos e respeitados pensadores da história da filosofia, e um ícone da filosofia moderna; esse pensador conseguiu delimitar os limites da razão na época em que viveu, realizando uma síntese entre o Racionalismo e o Empirismo. A filosofia de Kant demonstra aquilo que a razão pode ou não conhecer, a partir de uma postura crítica, superando a dicotomia então existente entre as escolas mencionadas (empirista e racionalista). Para tanto, o pensador prussiano investiga o que o ser humano racional é capaz de saber; o que deve fazer para atingir esse conhecimento; o que pode esperar (numa análise da esperança, ou mesmo da relação humana com a religião); e, finalmente, o que é o ser humano. Essa última indagação acaba sendo uma união dos três primeiros questionamentos e, portanto, uma pergunta fundamental.

O complexo pensamento de Kant, contudo, não é fácil de ser compreendido, demanda intenso estudo e reflexão para poder-se alcançar a sua profundidade e acuidade. Assim, este trabalho tem o intuito de colaborar com essa tarefa, somando-se aos demais estudos já existentes a respeito da filosofia kantiana, especialmente, procurando lançar algumas luzes sobre a questão do tipo da lei moral na forma tratada por Immanuel Kant em sua obra Crítica da Razão Prática (2016).

Em 1781 Kant publica a Crítica da Razão Pura, - talvez a obra mais célebre desse filósofo - na qual ele faz a análise da razão, em sua característica de subjetividade e capacidade de compreender os fenômenos que a ela se apresentam por meio dos sentidos e que, dessa forma, seriam seus objetos de conhecimento. Por outro lado, numa análise metafísica, estuda aquilo que chama de númenos, que nunca se apresentam aos sentidos, mas emergem do pensamento puro; entende que os numenos também podem ser objeto da razão metafísica. Nas palavras de Bonaccini (2012, p. 73), "A metafísica sempre ergueu a pretensão a um conhecimento além da experiência (a saber, a um conhecimento a priori, puramente racional)". 
Essa obra kantiana - Crítica da Razão Pura - em síntese, faz a análise do que a razão é capaz, o que pode ou não conhecer e como pode fazê-lo. Pela crítica, considera como pode ser compreendido o próprio conhecimento e, por meio da dialética transcendental, permite que ideias que não possuem aspectos possíveis de serem captados pelos sentidos, vale dizer, que não se apresentam ao sensivelmente ao pensamento, possam também ser conhecidas. Assim, por exemplo, a ideia de Deus ou de alma não se apresentam aos sentidos, mas suscitam questionamentos; tais perguntas não podem ser respondidas pelo critério da razão, mas podem ser analisadas por meio do uso da dialética transcendental, abrindo esta espaço, até mesmo, para o uso da fé.

Já a obra que se vincula diretamente ao objeto deste texto, a Crítica da Razão Prática, tem uma abordagem ligada às questões éticas, foi publicada em 1788, portanto, posteriormente àquela comentada acima. Em referido trabalho, Kant afirma que, livre das condições que limitam o conhecimento, o ser humano deve deduzir os princípios éticos de sua própria razão, que serão, assim, necessários, universais e desvinculados de sentimentos pessoais ou culturais. Tais princípios deverão se impor universalmente a todos, a qualquer tempo e em qualquer condição; a razão prática, de tal forma, adquire caráter legislador, outorga a lei moral. Perin (2018, p. 202) afirma textualmente que

O que Kant tem por certo na Crítica da razão prática ao conjecturar uma estratégia metodológica para a justificação do uso prático da razão é que a mesma não mais pode ser empreendida mediante uma passagem entre os domínios teórico e prático. Destarte, tanto a proposta, bem como o desdobramento e, ainda, o resultado da argumentação dessa obra sustentam precisamente a necessidade de que no próprio domínio prático seja legitimada uma legislação prática incondicionada e, também, que as consequências constitutivas desse empreendimento de legitimação tenham sua validade restrita ao âmbito intrínseco ao mesmo domínio.

Assim, no âmbito do uso da razão prática, e em seu aspecto legislador, é que Kant refere-se à questão do tipo da lei moral, o qual se pretende explicar ou, ao menos, facilitar sua correta compreensão, utilizando-se de um raciocínio que empregue uma analogia reversa ao tipo da lei penal. 


\section{DO USO DA RAZÃO PRÁTICA}

Para se chegar ao ponto pretendido neste texto, indispensável uma rápida exposição sobre os antecedentes lógicos a respeito do tipo da lei moral e da própria lei moral, contidos na Crítica da Razão Prática, sob pena de se tornar incompreensível o ponto àqueles que não tenham alguma familiaridade com o tema.

Na primorosa obra acima mencionada - Crítica da Razão Prática, Kant expõe e analisa a possibilidade do uso prático da razão, prescindindo, e até mesmo, recusando a influência de qualquer condicionante empírico, sensível, para sua formação; nessa função a razão é legisladora e, assim, autora da lei moral.

Demonstra o pensador em análise, que a razão, no seu uso prático, é responsável pela determinação geral da vontade do ser racional. Sendo conexa com a faculdade de desejar, a razão considerada como intenção não é sempre universal. Kant demonstra que esta vontade do ser racional, por sua vez, será determinada por princípios, que darão lugar a máximas, isto é, regras subjetivas, válidas apenas para a vontade de determinado sujeito. Máximas ou imperativos hipotéticos são, portanto, princípios, mas não são imperativos.

A vontade condicionada pela razão prática poderá ainda dar lugar às leis, que são objetivas, válidas universalmente e devem guiar a vontade de todo ser racional, independentemente das condições subjetivas que distinguem cada um desses seres. Essas leis, serão sempre corretas praticamente, e serão, por isso mesmo, categóricas, devendo sempre, reitera-se, guiar a vontade do ser racional, independentemente da possibilidade causal de se obter, na prática, determinado efeito desejado, vez que o resultado final pertence ao mundo sensível e não deve ser considerado para essa avaliação. Nas palavras de Perin (2018, p. 212), "Kant argumenta que uma legislação prática, desde que incondicionalmente determinante da vontade e, assim, válida para seres racionais em geral, pode unicamente ser concebida como autonomia da vontade". 
O imperativo categórico para Kant é incondicionado, exigindo que se aja sempre de acordo com a lei moral (ao passo que, o imperativo hipotético seria aquele condicional, quando um certo efeito é desejado). Assim, como afirma Ribeiro (2019, p. 32),

Kant argumenta que uma legislação prática, desde que incondicionalmente determinante da vontade e, assim, válida para seres racionais em geral, pode unicamente ser concebida como autonomia da vontade, ou seja, como '[...] aquela sua propriedade graças à qual ela é para si mesma a sua lei (independentemente da natureza dos objetos do querer)'.

Continuando seu raciocínio, Kant demonstra que o prazer ou desprazer, o agrado da vida, são subjetivos e não podem ser conhecidos a priori, portanto, o princípio que se fundamente nessa condição subjetiva poderá ser uma máxima, mas nunca uma lei.

As regras práticas materiais que dão origem a capacidades de desejar, como o agrado ou desagrado, são inferiores, sendo necessárias as condicionantes exclusivamente formais da vontade para que surjam as possibilidades de desejar superior, sem qualquer interferência do agradável ou desagradável, do prazer ou desprazer. Nas palavras de Kant, sem que esteja subordinada à "faculdade de desejar patologicamente determinável". (KANT, 2016, p. 41).

De tudo se conclui que, para Kant, só a razão prática pura, sem a interferência de quaisquer sentimentos, pode ser legisladora. Afirma ainda o filósofo que somente a vontade livre, vale dizer, a liberdade da vontade em obedecer unicamente a lei moral, sem qualquer condicionante empírico, dos fenômenos e da causalidade externa, pode ser considerada aquilo que denomina de liberdade transcendental.

Expõe que o conhecimento do incondicionalmente prático não pode, contudo, começar pelo conhecimento da liberdade, pois o ser racional finito não é imediatamente consciente dessa liberdade, ao contrário, ele começa pela criação de máximas, portanto, determinações pessoais, que se apresentam primeiramente ao indivíduo e que a razão faz perceber que não podem ser superadas por qualquer condição sensível, das quais são independentes e, assim, mostrando-se na condição 
de alcançar o patamar de lei moral. Só em seguida, a razão lhe faz perceber que tem a liberdade de agir de acordo com a lei moral.

Como a pretensão da legislação kantiana é a universalidade, um excerto da obra em estudo é considerado um dos melhores exemplos do anteriormente citado imperativo categórico. Tal enunciado, que não tem conteúdo material, mas tão somente horizonte formal é aquele que enuncia: "Aja de modo que a máxima de sua vontade possa sempre valer ao mesmo tempo como princípio de uma legislação universal." (KANT, 2016, p. 49).

Assim, a razão como vontade pura, sem qualquer condicionante, sem auxílio da experiência ou da vontade externa, que determina a vontade a priori pela forma de suas máximas, é legisladora.

A consciência dessa lei fundamental, que se impõe "por si mesma como proposição sintética a priori, que não está fundada em nenhuma intuição" pode-se denominar, segundo o autor, um fato da razão. E complementa o filósofo asseverando que se trata de um fato da razão pura que se anuncia como originalmente legisladora. (KANT, 2016, p. 51).

Essa razão pura prática, conforme Kant, fornece ao homem uma lei universal da qual se falou acima, que denomina de lei moral, válida para todos os seres racionais capazes de determinarem sua causalidade por meio da consciência de regras; a lei moral é, portanto, um imperativo categórico. Nessa condição o imperativo categórico é incondicionado em relação ao homem, o qual possui, em relação àquele, uma vinculação de obrigação, de dever, para poder buscar aproximar-se, num progresso infinito, daquilo que Kant denomina vontade santa. Esse imperativo categórico orientará suas máximas, em busca da virtude, ponto mais elevado que pode ser alcançado pelo ser racional finito.

A produção da lei moral pela razão pura prática é a demonstração da autonomia, da vontade pura, da liberdade no sentido positivo, em que todas as máximas produzidas pelo indivíduo entram em consonância com a lei prática. 
Ao contrário, se na produção de suas máximas o indivíduo deixar influir qualquer tema relacionado ao desejo, ao querer, contaminará a suas máximas pela heteronomia, vale dizer, retirando a pureza de suas máximas, que não criarão então nenhuma obrigação, ao contrário, serão opostas à lei moral.

Kant cita como exemplo, que nem mesmo a felicidade de outros seres, a felicidade de todos, pode ser colocada como condição de uma máxima, sem que retire sua autonomia e a impeça de transformar-se em lei; assim é, porque ela dependeria de um objeto a ser procurado em condições empíricas, dependeria da experiência e da opinião de cada indivíduo, não podendo, de tal forma, aplicar-se objetivamente a uma regra necessária e universal. Enquanto a máxima aconselha, a lei moral comanda e a obediência esse comando está sempre ao alcance da possibilidade de todos os seres racionais.

$\mathrm{Na}$ dedução dos princípios da razão prática pura, o autor demonstra que o mundo da natureza é sempre regido por leis e divide-se em duas esferas: a suprassensível, que seria uma natureza arquetípica, existente sob a autonomia da razão pura prática, independente do empirismo, cuja lei máxima é a lei moral, que, contudo, seu equivalente deve existir no mundo sensível, na natureza sensível dos seres, regida por leis empiricamente condicionadas, ou heterônomas que contém o efeito da primeira, a natureza ectípica.

Dessa forma, idealisticamente, se a capacidade física existente no mundo sensível fosse adequada, a obediência à lei moral produziria o sumo bem[3].

Prosseguindo em suas lições, Kant demonstra que a razão prática é a possibilidade da representação de um objeto, como um efeito possível da liberdade, a possibilidade ou impossibilidade de querer a ação pela qual o objeto seria tornado possível em havendo capacidade para tanto. Essa capacidade física para a efetiva obtenção do objeto é indiferente, o importante é saber se a lei moral nos autoriza a querer esse objeto, de maneira que o fundamento de determinação não é o objeto, mas a lei moral. 
Dessa maneira, os únicos objetos possíveis de uma razão prática são o bem e o mal. O bem como um objeto necessário, pois não é possível à razão não querer o bem e, o segundo, o mal, apenas como uma negação do bem. E este bem deve ser o bem em si mesmo, independentemente de julgamento de consequências boas, que é restrita a percepção pelos sentimentos de sujeitos individuais. Em outras palavras, para Kant o bem não pode ser mera consequência, mas criado pela liberdade volitiva.

Esse bem, portanto, deverá ser determinado pela vontade autônoma pois

a lei determina imediatamente a vontade, a ação que é conforme a lei é boa em si mesma, e uma vontade cuja máxima é sempre conforme essa lei, é boa absolutamente, em todos os propósitos, e é a condição suprema de todo o bem. (KANT, 2016, p. 90) - Grifos originais.

Prossegue explicando que bem e mal são modos de uma categoria única, a de causalidade, verdadeira demonstração da liberdade da razão, que assim se prova como prática.

\section{DO TIPO DA LEI MORAL}

Após a exposição acima, onde pretendeu-se introduzir pensamento de Kant a respeito da lei moral, de um maneira bastante esquemática e sem pretensão de grande profundidade, apenas para permitir alguma compreensão àqueles que não conhecem a obra analisada, busca-se agora, também com um propósito de exposição ilustrativa, abordar a questão do tipo da lei moral como tratado pelo autor na Crítica da Razão Prática.

Antes de se proceder a análise das lições do autor sobre a questão, vale-se aqui de um paralelo como meio de explicação simplificada; trata-se, dessa forma, de utilizarse do conceito de tipo utilizado na doutrina penal, portanto, de tipo penal, para procurar facilitar a compreensão do tipo da lei moral em Kant.

Tratam-se, é certo, de coisas diversas. O tipo da lei moral busca permitir a compreensão do mandamento para uma aproximação da consecução do sumo bem, ditado exatamente pela lei moral, emanada da razão pura e livre; ao contrário, o tipo 
penal, emanado do ordenamento jurídico positivado, tem como escopo fixar e esclarecer as condutas proibidas pelo direito penal em determinado tempo e local. Crê-se, contudo, que a análise comparativa possa ser, de alguma maneira, servível para fins meramente didáticos, facilitando a compreensão a respeito do tipo da lei moral.

Para tanto, lembra-se que o tipo penal é, grosso modo, uma proposição abstrata, uma regra abstrata, à qual uma determinada conduta concreta poderá eventualmente vir a subsumir-se, aperfeiçoando-se, dessa maneira, a figura do ilícito que era, reitere-se, apenas abstratamente nessa regra contida. Serve, portanto, para que se compreenda o mandamento contido na lei penal, que está em um mundo normativo e que poderá ser concretizado no universo sensível.

Em outras palavras, o tipo penal é a previsão legal e a descrição razoavelmente precisa de uma conduta proibida, que ora pode ser mais simples ou mais complexa, com todos os elementos e circunstâncias dessa conduta, que, contudo, não são a conduta em si mesmo; ao contrário, é uma mera descrição legal de uma conduta possível, que existe apenas em conceito e idealmente, não concretamente. Assim, o tipo penal é a "norma jurídica [que] prescreve imperativos do dever ser definidos sob a forma de proibições, de mandados e de permissões de ações dirigidas aos seres humanos" (SANTOS, 2017, p. 58).

A conduta humana pode, eventualmente, omitindo-se de praticar ações mandadas ou, ao contrário, exercendo ações proibidas, adequar-se, agora em concreto, àquela regra que antes já existia em abstrato, aperfeiçoando-se, então, o fato típico.

De maneira algo semelhante - embora com a diferença de fundamentos já mencionada antes - a lei moral tem apenas a razão livre para the dar origem; essa razão livre, contudo, não faz parte do mundo da natureza sensível e, mesmo assim, a lei moral deverá, ao menos idealisticamente, ser aplicada aos objetos dessa natureza. Conforme expõe Kant, o tipo da lei moral, permite que aquilo que foi dito na regra universal, in abstrato, seja observado em um objeto in concreto. Nas palavras de Mathias Netto (2020, p. 105), o tipo da lei moral diz: "Interroga-te a ti mesmo se a ação 
que projetas, no caso de ela ter de acontecer segundo uma lei da natureza de que tu próprio farias parte, a poderias ainda considerar como possível mediante a tua vontade."

De tal maneira, o tipo da lei moral deve possibilitar para a compreensão do ser racional finito, através de objetos concretos - portanto, que estão no mundo da natureza e que se apresentam aos sentidos através de suas formas - aquilo que é comandado pela lei. Dessa maneira, pode-se, exemplificativamente, dizer que uma Igreja pode ser tomada como tipo existente na natureza que permite a melhor compreensão da ideia da lei a respeito do bem.

Assim como no tipo penal a descrição abstrata da conduta não é o ilícito em si mesmo, também aqui, no tipo da lei moral, a possibilidade de subsunção de uma ação prática ou objeto do mundo sensível a uma lei prática pura, não faz com que a ação efetivamente aconteça ou se vincule ao mundo sensível, é, em verdade, apenas uma ilustração que facilita a compreensão.

Conforme leciona Kant,

a lei moral não tem nenhuma outra faculdade de conhecimento para mediar a aplicação dessa lei aos objetos da natureza, senão o entendimento (não a imaginação), o qual pode colocar sob uma ideia da razão, não um esquema da sensibilidade, mas uma lei em função da faculdade de julgar, e uma lei que possa ser apresentada in concreto nos objetos dos sentidos e, portanto, uma lei da natureza, mas apenas segundo sua forma, e nós podemos chama-la, por isso, de tipo da lei moral. (KANT, 2016, p. 98)

Dessa forma, a aplicação, a utilização, ou, para expressar de uma forma mais precisa, a observação do tipo da lei moral, facilita a compreensão pelo ser humano, racional que é, do mandamento dessa lei, mediante a observação de símbolos concretos.

\section{CONSIDERAÇÕES FINAIS}

Com a presente exposição e comparação do conceito de tipo da lei penal, apropriado de maneira esquemática a partir da teoria do tipo penal na doutrina respectiva, com o 
tipo da lei moral, da forma exposta por Kant na Crítica da Razão Prática, pretendeuse facilitar a compreensão do deste último.

Isso parece possível porque há uma similaridade entre esses tipos, ainda que às avessas, partindo o primeiro - tipo penal - do abstrato para ilustrar o concreto e, o segundo - tipo da lei moral - fazendo o caminho oposto, saindo do concreto e possibilitando-se alcançar a ideia contida na razão abstrata.

A similaridade entre as figuras comparadas encontra-se, como se demonstrou, que ambos se prestam a representações. No primeiro caso, o tipo penal, tem o caráter de utilização de símbolos abstratos para a compreensão do concreto; vale dizer, a lei penal parte de descrições abstratas de condutas humanas para levar o intérprete a compreender situações concretas que a ela se subsumam. Já no segundo caso, em relação ao tipo da lei moral kantiano, ocorre exatamente uma operação de racionalização inversa: o ser humano racional deverá, a partir da observação de símbolos concretos, objetos existentes na natureza e captados pelos sentidos, utilizálos como modelos para a compreensão do abstrato, ou seja, da lei moral.

\section{REFERÊNCIAS}

BONACCINI, Juan Adolfo. 0 argumento da estética e o problema da aprioridade: ensaio de um comentário preliminar. In: Comentários às obras de Kant: Crítica da Razão Pura. Joel Thiago Klein (Org.), Florianópolis: NEFIPO, 2012 - pp. 71 - 144.

KANT, Immanuel. Crítica da razão prática. Tradução de Monique Hulshof. Petrópolis: Vozes, 2016.

MATHIAS NETTO. Jayme. A função da imaginação: resolução da típica da lei moral em Kant. In: Polymatheia Revista de Filosofia, Universidade Estadual do Ceará UECE, v. 6, №. 9, 2013 - pp. 91 - 108. Disponível em: <http://seer.uece.br/?journal=PRF\&page=article\&op=view\&path\%5B\%5D=520\& path\%5B\%5D=585>. Acesso em: 20 abr. 2020. 
NASCENTES, Zama Caixeta. O sumo bem na filosofia prática de Kant. Orientador: Vinícius de Figueiredo. Dissertação (Mestrado). Universidade Federal do Paraná, Curitiba, $2004 . \quad$ Disponível em: $<$ https://acervodigital.ufpr.br/bitstream/handle/1884/34740/R\%20-\%20D\%20\%20ZAMA\%20CAIXETA\%20NASCENTES.pdf?sequence=1\&isAllowed $=y>$. Acesso em: 14 fev. 2019.

PERIN, Adriano. Kant e a estratégia metodológica da crítica da razão prática. In: Revista Dissertatio de Filosofia, Universidade Federal de Pelotas-RS - UFPel, no 29, Pelotas-RS, 2009 - pp. 201 - 225. E-ISSN 1983-8891. Disponível em: $<$ https://periodicos.ufpel.edu.br/ojs2/index.php/dissertatio/article/view/8828/5836>. Acesso em 18 out. 2018.

RIBEIRO, Elton Cândido. Kant e o fundamento da moralidade: um estudo da dedução do imperativo categórico em GMS III. Orientador: Mario Ariel González Porta. Dissertação (Mestrado). Pontifícia Universidade Católica de São Paulo - PUC-SP. Disponível em: https://tede2.pucsp.br/bitstream/handle/18785/2/Elton\%20Candido\%20Ribeiro.pdf>. Acesso em 27 abr. 2019.

SANTOS, Juarez Cirino dos. Direito penal: parte geral. $7^{\underline{a}}$ ed. rev., atual. e ampl. Florianópolis: Empório do Direito, 2017.

\section{APÊNDECE DE RODAPÉ}

[3] Importante registrar que o "sumo bem", para Kant, é, como menciona Nascentes (2019, p. 8), "a possibilidade da conexão sintética entre felicidade e moralidade, esta como condição de tornar-se digna daquela"

Enviado: Novembro, 2020.

Aprovado: Dezembro, 2020. 